\title{
THE PREVALENCE OF METABOLIC SYNDROME IN PATIENTS WITH OSTEOARTHRITIS OF KNEE ATTENDING PHYSICAL MEDICINE AND REHABILITATION DEPARTMENT OF A TERTIARY CARE CENTRE
}

\author{
Anit Antony1, Roy Rama Chandran², Abdul Gafoor Shahulhameed ${ }^{3}$, Sonu Mohan Mohanan Sudha ${ }^{4}$, Soumya Viswanath ${ }^{5}$ \\ ${ }_{1}^{1}$ Junior Resident, Department of Physical Medicine and Rehabilitation, Govt. Medical College, Kozhikode, Kerala. \\ ${ }^{2}$ Assistant Professor, Department of Physical Medicine and Rehabilitation, Govt. Medical College, Kozhikode, Kerala. \\ ${ }^{3}$ Professor and HOD, Department of Physical Medicine and Rehabilitation, Govt. Medical College, Kozhikode, Kerala. \\ ${ }^{4}$ Junior Resident, Department of Physical Medicine and Rehabilitation, Govt. Medical College, Kozhikode, Kerala. \\ ${ }_{5}^{5}$ Senior Resident, Department of Physical Medicine and Rehabilitation, Govt. Medical College, Kozhikode, Kerala.
}

ABSTRACT

\section{BACKGROUND}

Osteoarthritis $(\mathrm{OA})$ is a degenerative joint disease, occurring primarily in older persons. It is the fourth leading cause of Years Lived with Disability (YLD). OA has become a major health problem now; not only because of its increasing prevalence worldwide but also because of its frequent association with cardiovascular disease, the leading cause of death in industrialised countries. There is growing evidence that $\mathrm{OA}$ is not simply a disease related to aging or mechanical stress of joints, but rather a "metabolic disorder" in which various interrelated metabolic derangements contribute to the initiation and progression of the disease process. It is a misnomer to label osteoarthritis as a purely degenerative arthritis. It is now clear that an active genetic and proteomic profile suggests inflammation. The cytokine milieu is similarly inflammatory and parallels that found in the Metabolic Syndrome (Met S). Met $\mathrm{S}$ is a constellation of metabolic risk factors that directly promotes the development of cardiovascular disease and increases risk for developing Type 2 diabetes.

This study is aimed to determine the prevalence of metabolic syndrome in patients with OA knee.

\section{MATERIALS AND METHODS}

It is a descriptive study, which was conducted at Lifestyle diseases management clinic of the Department of Physical Medicine and Rehabilitation, Govt. Medical College, Kozhikode; including 150 subjects with Osteoarthritis of knee as cases and 80 subjects without Osteoarthritis as controls and the prevalence of metabolic syndrome was studied in both these groups.

\section{RESULTS}

The study observed that metabolic syndrome was present in $72 \%$ of cases and only in $37.5 \%$ among control group.

\section{CONCLUSION}

There is significant association between osteoarthritis of knee and metabolic syndrome ( $\mathrm{p}$ value of 0.000 ). The association metabolic syndrome with osteoarthritis of knee was more in females. Among the metabolic profile abnormalities; there was significant association of hypertension with osteoarthritis. The association between hypertension and osteoarthritis of knee was also more among females.

\section{KEYWORDS}

Metabolic Syndrome; Osteoarthritis of knee.

HOW TO CITE THIS ARTICLE: Antony A, Chandran RR, Shahulhameed AG, et al. The prevalence of metabolic syndrome in patients with osteoarthritis of knee attending physical medicine and rehabilitation department of a tertiary care centre. J. Evolution Med. Dent. Sci. 2017;6(40):3175-3180, DOI: 10.14260/Jemds/2017/686

\section{BACKGROUND \\ Osteoarthritis (OA) is a degenerative joint disease, occurring primarily in older persons, characterised by erosion of the articular cartilage, formation of osteophytes; which are hypertrophy of bone at the margins, subchondral sclerosis and a range of biochemical and morphologic alterations of the synovial membrane and joint capsule. ${ }^{1}$ It is the most common type of arthritis affecting 27 million adults in US. ${ }^{2}$}

Financial or Other, Competing Interest: None.

Submission 11-04-2017, Peer Review 04-05-2017,

Acceptance 11-05-2017, Published 18-05-2017.

Corresponding Author:

Dr. Roy Rama Chandran,

Assistant Professor,

Department of Physical Medicine

\& Rehabilitation, Govt. T. D. Medical College,

Vandanam, Alappuzha-688005, Kerala.

E-mail: royramachandran@gmail.com

DOI: $10.14260 /$ jemds $/ 2017 / 686$

(c) $(1)$
In industrialised societies, $\mathrm{OA}$ is the leading cause of physical disability, increases in healthcare usage and impaired quality of life affecting $60 \%-70 \%$ of the population older than 60 years. $^{3}$ The worldwide prevalence estimate for symptomatic $\mathrm{OA}$ is $9.6 \%$ among men and $18 \%$ among women. It is the fourth leading cause of Year Lived with Disability (YLD). ${ }^{4}$ In India, the overall prevalence of osteoarthritis in the elderly is $56.6 \% 5$; $\mathrm{OA}$ is more common in females as compared to males (70.1\% vs. $41.6 \%){ }^{6}$

Osteoarthritis is rapidly becoming a significant medical and financial burden in a world whose population is ageing. ${ }^{7}$ It affects both working and retired individuals and has a broad economic burden on health. The pathophysiological mechanisms of $\mathrm{OA}$ are under debate, but there is general agreement that biomechanics and increased dynamic loading of the joint are involved. ${ }^{8}$ Various risk factors such as ageing, female gender, obesity, repetitive joint loading 9 (occupational and leisurely physical activities) and previous knee injury have been reported. ${ }^{10-12}$ 
Above all obesity is the most important risk factor, because it remains a matter of possible improvement. There is debate about how obesity contributes to knee OA. It is most commonly considered that excessive and/or misdirected biomechanical load stimulate excess osteoblasts or chondrocyte biosynthesis in the bone or cartilage. ${ }^{13}$ On the other hand, the association between obesity and knee $\mathrm{OA}$ as well as finger $\mathrm{OA}$ has been reported. ${ }^{14}$ Another theory is that joint health is affected by a generalised negative metabolic environment reflecting a systemic inflammatory response or response to the secretory products of adipose tissues. ${ }^{15-17}$ However, there is little consensus regarding the latter theory.

There are evidences that $\mathrm{OA}$ is not simply a disease related to aging or mechanical stress of joints, but rather a "metabolic disorder" in which various interrelated lipid, metabolic and humeral mediators contribute to the initiation and progression of the disease progression. Indeed, $\mathrm{OA}$ is linked not only to obesity but also to other cardiovascular risk factors namely diabetes, dyslipidaemia, hypertension and insulin resistance. It is actually a misnomer to label osteoarthritis as a purely degenerative arthritis. It is now clear that an active genetic and proteomic profile suggests inflammation. The cytokine milieu is similarly inflammatory and nearly parallels that found in the metabolic syndrome. ${ }^{18}$

Two main theories have been proposed to explain this association between obesity and OA: the biomechanical and the systemic/metabolic. ${ }^{19}$ The biomechanical hypothesis proposes that obesity leads to an increased loading of the (knee) joints beyond their capabilities (due to the increased body weight). Mechanical overload represents a direct physical insult to the cartilage matrix. Additionally, mechanical forces are transmitted to the cells and transformed into intracellular signals, triggering a variety of cellular responses including the release of paracrine or autocrine factors. With increased mechanical stress, cells are overstrained and fail to perform adequately. ${ }^{19}$

The systemic/metabolic hypothesis proposes that metabolic factors related to obesity act directly or indirectly on chondrocytes leading to the increased risk for developing OA. ${ }^{20}$ Several studies suggest that adipokines (proteins synthesised and secreted mostly by adipocytes) are the major factors linking obesity to OA. Leptin, the prototypic adipokine, has been found in cartilage of $\mathrm{OA}$ patients and shows biologic activity on chondrocytes. It has been shown to act as a pro-inflammatory cytokine and a catabolic factor in cartilage metabolism via induction of MMPs. Conversely, it might also demonstrate anabolic effects through the stimulation of proteoglycan and collagen synthesis and the induction of growth factors. Visfatin is one of the adipokines, which has been recently studied as a pro-degradative mediator for cartilage. ${ }^{21}$ Adiponectin, negatively associated with body mass index, is negatively associated with progression of hand 0 A. ${ }^{21}$

A third (indirect) effect of obesity is the induction of a (latent) diabetic metabolic state in the obese patients, overtime, enhancing for example advanced glycation end products formation within the cartilage matrix and leading to all their detrimental effects on matrix mechanoproperties and cell behaviour. ${ }^{19}$ Recently, diabetes was associated with risk for bilateral knee $\mathrm{OA}$ and hypercholesterolaemia independently associated with generalised OA.
The metabolic syndrome is a constellation of interrelated risk factors of metabolic origin-metabolic risk factors-that appear to directly promote the development of Atherosclerotic Cardiovascular Disease (ASCVD). ${ }^{22}$ Patients with the metabolic syndrome also are at increased risk for developing type 2 diabetes mellitus. The most widely recognised of the metabolic risk factors are dyslipidaemia, elevated blood pressure and elevated plasma glucose level. Individuals with these characteristics commonly manifest a prothrombotic state and a pro-inflammatory state and so at an elevated risk for Cardiovascular Diseases (CVD). Atherogenic dyslipidaemia consists of an aggregation of lipoprotein abnormalities including elevated triglycerides and apolipoprotein $B(A p o B)$, increased small LDL particles and a reduced level of HDL cholesterol (HDL-C) which is the good cholesterol. The metabolic syndrome is truly a grouping of cardiovascular disease risk factors, but one that probably has more than one cause. The magnitude of the increased risk of CVD can vary according to which components of the syndrome are present plus the other, non-metabolic syndrome risk factors in a particular person. The predominant underlying risk factors for the syndrome appear to be truncal obesity and insulin resistance; other associated conditions can be physical inactivity, ageing and hormonal imbalance.

The National Cholesterol Education Program (NCEP), Adult Treatment Panel III (ATP III) introduced clinical criteria for defining the metabolic syndrome. In doing so, the purpose of ATP III was to identify people at higher long-term risk for cardiovascular disease who deserved aggressive clinical lifestyle intervention early to reduce risk. The ATP III criteria did not require demonstration of insulin resistance per se. It was noted that direct measures of insulin resistance are laborious and not standardised. The ATP III criteria thus required no single factor for diagnosis, but instead made the presence of 3 of 5 factors for establishing the diagnosis.

\section{Criteria for Metabolic Syndrome}

1. Waist circumference $\geq 90 \mathrm{~cm}$ in males and $\geq 80 \mathrm{~cm}$ in females.

2. Fasting plasma glucose $\geq 100$ or type 2 diabetes mellitus, on treatment.

3. Systolic blood pressure $\geq 130 \mathrm{mmHg}$ or diastolic blood pressure $\geq 85 \mathrm{mmHg}$ or hypertension on treatment.

4. In fasting lipid profile, triglycerides $\geq 150 \mathrm{mg} / \mathrm{dL}$.

5. $\mathrm{HDL}<50 \mathrm{mg} / \mathrm{dL}$ in females and $<40 \mathrm{mg} / \mathrm{dL}$ in males.

Presence of three of the above criteria is required for the diagnosis of metabolic syndrome. IDF recognised and emphasised ethnic differences in the correlation between abdominal obesity and other metabolic syndrome risk factors. For this reason, criteria of abdominal obesity were specified by nationality or ethnicity based on best available population estimates. For Asian populations except for Japan, thresholds were $\geq 90 \mathrm{~cm}$ in men and $\geq 80 \mathrm{~cm}$ in women. ${ }^{19}$

In rehabilitation medicine, we come across a large population of patients with osteoarthritis of knee. There have been several studies citing the association of metabolic abnormalities with osteoarthritis of knee in Asian population. Unfortunately, not many studies have been conducted in this regard in the field of rehabilitation medicine in India. The findings of this study may help in improving the health status 
of every patient with osteoarthritis of knee and to reduce chances of cardiovascular diseases among them. Hence, this study is appropriate.

\section{MATERIALS AND METHODS}

The study entitled- "The prevalence of metabolic syndrome in patients with osteoarthritis of knee attending Physical Medicine and Rehabilitation Department of a Tertiary Care Centre" was a hospital-based descriptive study carried out in the Outpatient Department and Lifestyle Disease Management Clinic, Department of Physical Medicine and Rehabilitation, Government Medical College, Kozhikode, during a period of one year from March 2013 - February 2014.

The study group comprised of 230 subjects including 150 cases and 80 controls; 150 persons diagnosed with osteoarthritis of knee based on clinical and radiological evidence in the age group 25 - 70 years were taken as cases and 80 persons without osteoarthritis belonging to the same age group were taken as controls.

The test group was chosen from a random selection of patients who appeared for a special knee pain clinic at the Dept. of Physical Medicine and Rehabilitation conducted every week for a period of one year. Three cases were chosen every week out of 30 patients in average who appeared in one day for 50 weeks. They were then evaluated at the Lifestyle Diseases Clinic.

Controls were selected by random selection. A simple questionnaire was distributed to patients attending the OPD with queries regarding presence of symptoms of knee pain and also their willingness to participate in the study. An average of 20 subjects without any knee pain gave consent for the study weekly and from among them 2 were randomly selected to the control sample. The process was done for 40 weeks and a control group of 80 subjects was obtained. The selected persons were evaluated at the Lifestyle Diseases Clinic.

\section{Inclusion Criteria}

1. Osteoarthritis of knee for cases.

2. Both genders.

3. Age $25-70$ years.

4. Ambulant persons.

\section{Exclusion Criteria}

1. History of trauma to knee.

2. Congenital deformities of lower limb.

3. Lower limb amputees.

4. Coagulation disorders.

5. Persistent neurological deficits.

6. Infective and inflammatory arthritis.

\section{Description of Methods}

Osteoarthritis of knee was diagnosed according to the ACR (American College of Rheumatology) clinical and radiologic criteria.

\section{Clinical}

1. Knee pain for most days or prior months.

2. Crepitus on active joint motion.

3. Morning stiffness lasting 30 minutes or less.

4. Age 38 years or older.
5. Bony enlargement of the knee on examination.

OA if the items $1,2,3,4$ or $1,2,5$ or $1,4,5$ are present.

\section{Clinical and Radiographic}

1. Knee pain for most days or prior months.

2. Osteophytes at joint margins on radiographs.

3. Synovial fluid typical of OA (laboratory).

4. Age 40 years or older.

5. Crepitus on active joint motion.

6. Morning stiffness lasting 30 minutes or less.

OA if the items 1,2 or $1,3,5,6$ or $1,4,5,6$ are present.

After obtaining an informed consent, anthropometric measurements were taken. Body weight was measured using a digital floor scale and standing height using a wall mounted stadiometer. BMI was calculated as weight in kilograms divided by height in squared meters $\left(\mathrm{kg} / \mathrm{m}^{2}\right)$. Waist circumference was measured in centimetres $(\mathrm{cm})$ using a non-stretchable measuring tape just above the level of umbilicus at the end of normal expiration with the patient standing, relaxed and hands freely hanging by the side. Blood pressure was measured using a sphygmomanometer in the right upper limb in the sitting position.

\section{The following Investigations were done}

Fasting venous Plasma Glucose (FPG) and Fasting Lipid Profile (FLP).

\section{Analytical Methods}

Obesity was defined by a BMI $\geq 25 \mathrm{~kg} / \mathrm{m} 2$. BMI between 18.5 $\mathrm{kg} / \mathrm{m} 2-22.9 \mathrm{~kg} / \mathrm{m} 2$ was taken as normal and $23 \mathrm{~kg} / \mathrm{m} 2$ $24.9 \mathrm{~kg} / \mathrm{m} 2$ was overweight. (In accordance with Health Ministry of India's diagnostic cut-offs for BMI 2008).

\section{Metabolic Syndrome}

Was defined according to the consensus definition for adult Asian Indians. NCEP, ATP III recommends that three out of five clinical and/or biochemical abnormalities should be present to satisfy this labelling-

1. Abdominal obesity (Waist circumference in $\mathrm{cm}$ ): Males $\geq 90 \mathrm{~cm}$ and Females $\geq 80 \mathrm{~cm}$.

2. Dysglycaemia (Fasting Plasma Glucose): $\geq 100$ or known case of diabetes mellitus.

3. Hypertension: Systolic BP > $130 \mathrm{mmHg}$ and/or Diastolic BP > $85 \mathrm{mmHg}$ or known case of hypertension.

4. In Fasting Lipid Profile, raised triglycerides $\geq 150$ $\mathrm{mg} / \mathrm{dL}$.

5. Low HDL: $<40 \mathrm{mg} / \mathrm{dL}$ in males and $<50 \mathrm{mg} / \mathrm{dL}$ in females.

\section{Statistical Analysis}

All the data were coded and entered in Microsoft Excel Sheet, rechecked and analysed with SPSS-16 statistical software using descriptive statistics and odds ratio.

One hundred and fifty people with Osteoarthritis were randomly selected for the study with 80 people as controls. All were assessed for their exposure to Osteoarthritis and Metabolic Syndrome. The odds ratio of Metabolic Syndrome versus Osteoarthritis was 4.286 (95\% CI, 2.409 to 7.625). The results show that odds of having Metabolic Syndrome are 
4.286 times greater in people with Osteoarthritis (cases) than in people without Osteoarthritis (controls). In other words, people who had Osteoarthritis were 4.286 times more likely to have Metabolic Syndrome than people who did not have Osteoarthritis.

The age distribution of the study group was between 25 70 years with mean age of 52.21 years among cases (57.32 in males and 51.33 in females) and 49.75 years among controls (52.07 in males and 49.26 in females). The mean age was comparable in both groups. The study group comprised a majority of females.

The mean BMI was $28.55 \mathrm{~kg} / \mathrm{m} 2$ among the cases and $29.71 \mathrm{~kg} / \mathrm{m} 2$ among the controls; $71 \%$ of cases and $82.5 \%$ of controls were obese. Obesity was more common among females.

\section{RESULTS}

Metabolic syndrome was present in $72 \%$ cases compared to $37.5 \%$ of controls. This association between metabolic syndrome and osteoarthritis of knee was found to be statistically significant with 'p' value of 0.000 . (Table 1 and Figures 1 and 2).

The following were the Metabolic Profile Abnormalities Detected in the Study-

\section{Hypertension}

Hypertension was present in $59.3 \%$ of cases and $43.8 \%$ of controls and this difference was statistically significant with a $\mathrm{p}$ value of 0.024 . Hypertension was more common among females with osteoarthritis knee compared to males and this difference was statistically significant with a ' $p$ ' value of 0.004 .

\section{Dysglycaemia}

Dysglycaemia or abnormal fasting plasma glucose was present in $54 \%$ of cases and $52.5 \%$ of controls; $68.2 \%$ of males and $51.6 \%$ of females with osteoarthritis knee had abnormal fasting plasma glucose. Among the cases, 27.3\% were diabetic. We did not find any association between dysglycaemia and OA knee.

\section{Lipid Profile Abnormalities}

Raised total cholesterol ( $>200 \mathrm{mg} / \mathrm{dL}$ ) was present in $62 \%$ of cases and $57.5 \%$ of controls. Raised triglycerides (> 150 $\mathrm{mg} / \mathrm{dL}$ ) was seen in $26 \%$ of cases and $23.8 \%$ of controls. Reduced HDL was seen in $54.7 \%$ of cases and $50 \%$ of controls. LDL was high ( $>160 \mathrm{mg} / \mathrm{dl})$ in $32 \%$ of cases and $23.75 \%$ of controls. There was no association between dyslipidaemia and OA knee in our study.

\section{The Anthropometric Abnormalities Detected were:}

Increased waist circumference was observed in $86.7 \%$ of cases (50\% in males and $93 \%$ in females) and $87.5 \%$ of controls. Abdominal obesity was more common in females among both cases and controls.

The mean BMI was 28.55 (25.01 in males and 29.16 in females) amongst the cases and 29.71 amongst the controls.

\section{Gender Distribution of Metabolic Syndrome among Cases} and Controls

Metabolic syndrome was present in $77.3 \%$ of female cases compared to $40.9 \%$ of male cases. The association of metabolic syndrome with knee osteoarthritis in females was statistically significant with 'p' value of 0.000 . (Table 2 and Figure 3).

\begin{tabular}{|c|c|c|}
\hline Metabolic Syndrome & Cases & Controls \\
\hline Present & $108(72 \%)$ & $30(37.5 \%)$ \\
\hline Absent & $42(28 \%)$ & $50(62.5 \%)$ \\
\hline \multicolumn{2}{|c|}{ Table 1 } \\
\hline
\end{tabular}

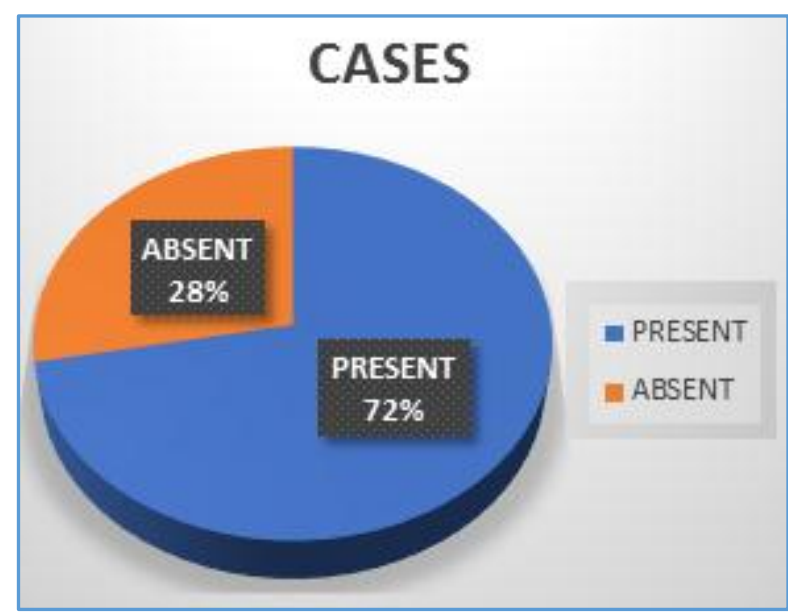

Figure 1

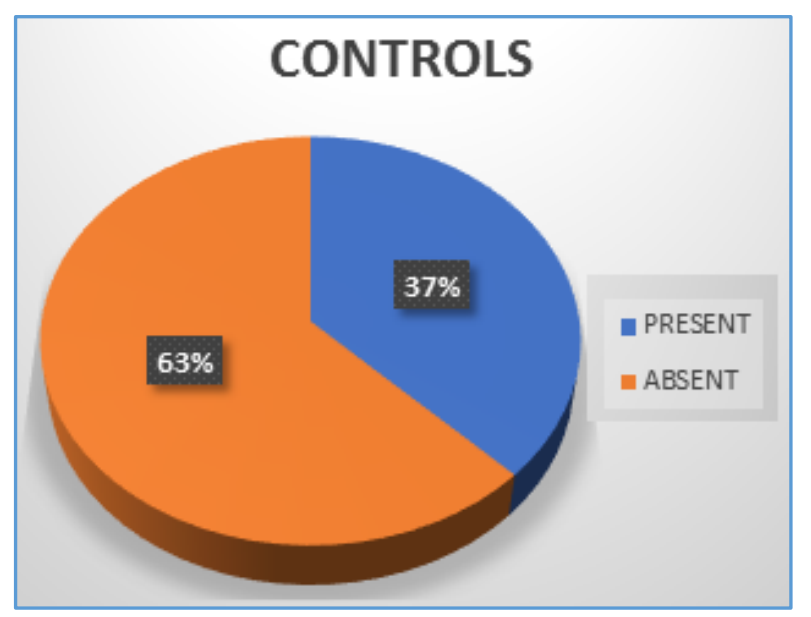

Figure 2

\begin{tabular}{|c|c|c|}
\hline & MetS Absent & MetS Present \\
\hline Male Cases & $13(59.1 \%)$ & $9(40.9 \%)$ \\
\hline Male Controls & $11(78.6 \%)$ & $3(21.4 \%)$ \\
\hline Female Cases & $29(22.7 \%)$ & $99(77.3 \%)$ \\
\hline Female Controls & $39(59.1 \%)$ & $27(40.9 \%)$ \\
\hline \multicolumn{2}{|c|}{ Table 2 } \\
\hline
\end{tabular}

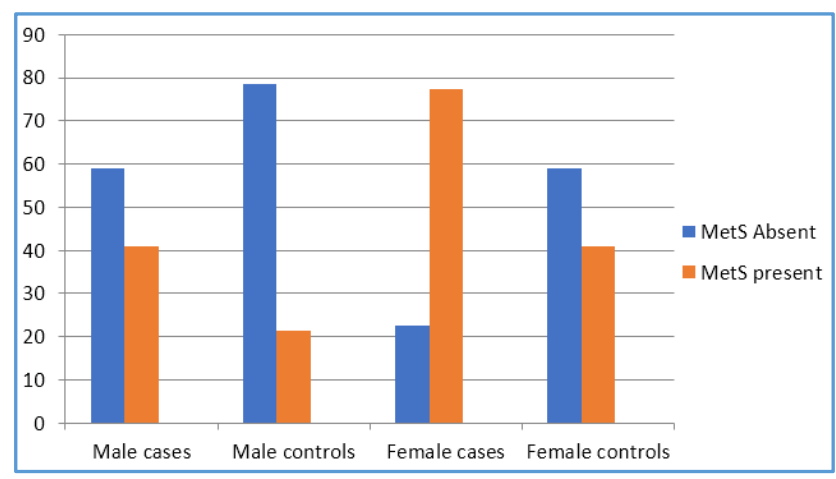

Figure 3 


\section{DISCUSSION}

Osteoarthritis of knee is one of the most common musculoskeletal conditions. In our study, we found a statistically significant association between osteoarthritis of knee and metabolic syndrome. The association was found more significant in females. Our results are very close to the findings of the following studies.

Engstrom et $\mathrm{al}^{8}$ found that the presence of metabolic syndrome correlated significantly with osteoarthritis of the knees. However, this relationship ceased to exist after adjustment for BMI. In the Japanese study by Ryo Inoue et $\mathrm{al}^{23}$ the prevalence rates of both metabolic syndrome and knee OA tended to increase with age. Although, there was no association between metabolic syndrome and knee $\mathrm{OA}$ in males, the presence of knee OA was significantly associated with that of metabolic syndrome in females. In the US National HANES (NHANES III; 1988-1994) study, metabolic syndrome was more prevalent in persons with $\mathrm{OA}$ from among > 7,000 adults. ${ }^{24}$ In the Michigan Bone Health and Metabolism Study, in obese woman the presence of two or more cardiometabolic risk factors was associated with more reports of persistent knee pain over the previous 3 years. ${ }^{25}$ In the Japanese Research into Osteoarthritis Against Disability (ROAD) study, the odds of OA increased with the presence of each additional component of MetS. Furthermore, in a Russian study in 1,350 individuals with OA $62.56 \%$ were also diagnosed with MetS. ${ }^{26}$

Our study also found out an association between hypertension and OA knee. The association of metabolic syndrome with $\mathrm{OA}$ knee indicates the high risk of cardiovascular diseases in these patients. As OA knee is a common problem encountered in rehabilitation medicine, further longitudinal studies are required to establish a causal association between OA knee and metabolic syndrome. Also, all patients with OA knee should be evaluated in detail to identify underlying metabolic abnormalities and treated accordingly, so that we can reduce future disabilities especially those related to cardiovascular diseases.

\section{CONCLUSION}

1. Metabolic syndrome was more common among persons with osteoarthritis of knee and the association was statistically significant.

2. Association of metabolic syndrome with osteoarthritis of knee was more in females.

3. Among the metabolic profile abnormalities, there was significant association of hypertension with osteoarthritis.

4. The association between hypertension and osteoarthritis of knee was also more among females.

5. All patients with OA knee should be evaluated to identify underlying metabolic abnormalities and treated accordingly, so that we can reduce future disabilities related to cardiovascular diseases.

\section{Limitations of the Study}

1. The sample size was small, number of male subpopulation smaller.

2. Due to practical constraints in making a patient without a knee pain to undergo metabolic syndrome screening, the number of participants in the control group was low. So the chances of bias due to confounding factors were high.

3. It was a hospital-based study, and hence may not be representative of general population.

\section{REFERENCES}

[1] Cesare PED, Haudenschild DR, Samuels J, et al. Pathogenesis of osteoarthritis. Part 15. Chapter 98. In: Firestein GS, Budd RC, Gabriel SE, et al. eds. Kelley's Textbook of rheumatology. Vol II. 9th edn. Saunders 2013:1617-35.

[2] Lawrence RC, Felson DT, Helmick CG, et al. Estimates of the prevalence of arthritis and other rheumatic conditions in the United States. Part II. Arthritis Rheum 2008;58(1):26-35.

[3] Patil PS, Dixit UR, Shettar CM. Risk factors of osteoarthritis knee - a crosssectional study. IOSR Journal of Dental and Medical Sciences 2012;2(5):0810.

[4] Salve H, Gupta V, Palanivel C, et al. Prevalence of knee osteoarthritis amongst perimenopausal women in an urban resettlement colony in South Delhi. Indian Journal of Public Health 2010;54(3):155-7.

[5] Sharma MK, Swami HM, Bhatia V, et al. An epidemiological study of correlates of osteo-arthritis in geriatric population of UT Chandigarh. Indian J Community Med 2007;32(1):77-8.

[6] Chopra A, Patil J, Billampelly V, et al. The Bhigwan (India) COPCORD: methodology and first information report. APLAR J Rheum 1997;1:145-54.

[7] Herndon JH, Davidson SM, Apazidis A. Recent socioeconomic trends in orthopaedic practice. J Bone Joint Surg Am 2001;83(7):1097-105.

[8] Engstrom G, De Verdier GM, Rollof J, et al. C-reactive protein, metabolic syndrome and incidence of severe hip and knee osteoarthritis. A population-based cohort study. Osteoarthr Cartil 2009;17(2):168-73.

[9] Felson DT. Osteoarthritis. Section 3. Part 15. Chapter 332. In: Fauci AS, Kasper DL, Longo DL, et al. eds. Harrison's principles of internal medicine. Vol II. $18^{\text {th }}$ edn. McGraw-Hill 2012:2828-36.

[10] Hart DJ, Doyle DV, Spector TD. Incidence and risk factors for radiographic knee osteoarthritis in middleaged women: the Chingford study. Arthritis Rheum 1999;42(1):17-24.

[11] Cooper C, McAlindon T, Coggon D, et al. Occupational activity and osteoarthritis of the knee. Ann Rheum Dis 1994;53(2):90-3.

[12] Roos H, Laure'n M, Adalberth $T$, et al. Knee osteoarthritis after meniscectomy: prevalence of radiographic changes after twenty one years, compared with matched controls. Arthritis Rheum 1998;41(4):687-93.

[13] Elder SH, Kimura JH, Soslowsky LJ, et al. Effect of compressive loading on chondrocyte differentiation in agarose cultures of chick limb-bud cells. J Orthop Res 2000;18(1):78-86. 
[14] Hart DJ, Spector TD. The relationship of obesity, fat distribution and osteoarthritis in women in the general population: the Chingford Study. J Rheumatol 1993;20(2):331-5.

[15] Hart DJ, Doyle DV, Spector TD. Association between metabolic factors and knee osteoarthritis in women: the Chingford study. J Rheumatol 1995;22(6):1118-23.

[16] Sowers M, Jannausch M, Stein E, et al. C-reactive protein as a biomarker of emergent osteoarthritis. Osteoarthr Cartil 2002;10(8):595-601.

[17] Acheson RM, Collart AB. New Haven survey of joint diseases. XVII. Relationship between some systemic characteristics and osteoarthrosis in a general population. Ann Rheum Dis 1975;34(5):379-87.

[18] Velasquez MT, Katz JD. Osteoarthritis: another component of metabolic syndrome? Metabolic Syndrome and Related Disorders 2010;8(4):295-305.

[19] Aigner T, Schmitz N. Pathogenesis and pathology of osteoarthritis. Section 13. Chapter 173. In: Hochberg MC, Silman AJ, Smolen JS, et al. eds. Hochberg textbook of rheumatology. Vol 2. $5^{\text {th }}$ edn. Elsevier 2011: 1741-60.

[20] Loeser RF. Systemic and local regulation of articular cartilage metabolism: where does leptin fit in the puzzle? Arthritis Rheum 2003;48(11):3009-12.

[21] Conde J, Scotece M, Gómez R, et al. Adipokines and osteoarthritis: novel molecules involved in the pathogenesis and progression of disease. Article ID 203901 Arthritis 2011;(2011):8.
[22] Grundy SM, Cleeman JI, Daniels SR, et al. Diagnosis and management of the metabolic syndrome an American Heart Association/National Heart, Lung, and Blood Institute Scientific Statement. Circulation 2005;112(17):2735-52.

[23] Inoue R, Ishibashi $Y$, Tsuda E, et al. Medical problems and risk factors of metabolic syndrome among radiographic knee osteoarthritis patients in the Japanese general population. J Orthop Sci 2011;16(6):704-9.

[24] Singh G, Miller JD, Lee FH, et al. Prevalence of cardiovascular disease risk factors among US adults with self-reported osteoarthritis: data from the Third National Health and Nutrition Examination Survey. Am J Manag Care 2002;8(Suppl 15):S383-S91.

[25] Sowers M, Karvonen-Gutierrez CA, Palmieri-Smith R, et al. Knee osteoarthritis in obese women with cardiometabolic clustering. Arthritis Rheum 2009;61(10):1328-36.

[26] Yoshimura N, Muraki S, Oka H, et al. Association of knee osteoarthritis with the accumulation of metabolic risk factors such as overweight, hypertension, dyslipidemia and impaired glucose tolerance in Japanese men and women: the ROAD study. J Rheumatol 2011;38(5):921-30. 